\title{
An Additional Perspective on Proton Pump Inhibitors as Risk Factors for COVID-19
}

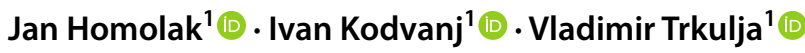 \\ Accepted: 23 January 2021 / Published online: 19 February 2021 \\ (c) The Author(s), under exclusive licence to Springer Nature Switzerland AG part of Springer Nature 2021
}

\section{Dear Editor,}

We read with great interest a recent paper in Clinical Drug Investigation by Charpiat et al. entitled "Proton Pump Inhibitors are Risk Factors for Viral Infections: Even for COVID19?" [1]. The authors discuss potential implications of the use of proton pump inhibitors (PPIs) amidst the COVID-19 pandemic and suggest they should be used with caution as (i) alkalinisation of gastric acid removes the protective barrier towards ingested microorganisms; (ii) PPI treatment has been proposed as a risk factor for some viral infections (rotavirus, influenza virus, norovirus, and Middle East respiratory syndrome coronavirus); and (iii) evidence of faecal-oral transmission has been reported for SARS-CoV-2. Considering the widespread use of PPIs and the serious situation regarding the ongoing COVID-19 pandemic, we recognise the manuscript by Charpiat et al. as highly relevant and wish to put forward an additional perspective that is pertinent to the discussion of PPIs as risk factors for COVID-19.

\section{PPIs and Viral Infections}

As argued by Charpiat et al, PPIs have been associated with an increased risk of some viral infections (e.g. [2, 3]). However, as emphasised in a comprehensive review on acid-suppressive therapy and the risk of infections, "data on pathophysiology and clinical significance of acid suppression drugs in human viral infections are scarce" [4] and not indicative of increasing risk mediated by alkalinisation of the gastric acid. A systematic review/meta-analysis of high-quality randomised, double-blind, placebo-controlled

This letter is related to article available at https://doi.org/10.1007/ s40261-020-00963-x.

Jan Homolak

homolakjan@gmail.com

1 Department of Pharmacology, University of Zagreb School of Medicine, 10000 Zagreb, Croatia trials of PPIs in patients with gastro-oesophageal reflux disease or peptic ulcer disease failed to detect an association between the treatment and respiratory infections reported as adverse events [5]. High-quality pharmacoepidemiological studies have indicated an increased risk of gastroenteritis during periods of highest circulation of enteric viruses in continuous PPI users versus non-users (RR 1.81, $95 \%$ CI 1.72-1.90) [3], but failed to demonstrate an association between PPIs (or histamine $\mathrm{H}_{2}$ receptor antagonists) in new nonsteroidal anti-inflammatory drug users and the risk of hospitalisation for community-acquired pneumonia [6]. In contrast, some authors have suggested that PPIs should be investigated as potential treatment for viral infections [7]; however, it should be emphasised that, at the moment, this has only been supported by sporadic in vitro experiments and indirect findings.

The complex relationship between PPIs and viral infections dates back to the time of their invention and synthesis of timoprazole, a drug that would later become a prototype of novel antisecretory agents. A core antisecretory compound used by Hässle (Astra) in the process of development of the first PPI, pyridyl-2-acetamide, was originally obtained from Servier as an antiviral agent. Conversion to pyridyl-2-thioacetamide, followed by the introduction of benzimidazole ring and addition of sulfoxide (as the obtained compound was already covered by a Hungarian patent) yielded a completely new group of drugs known today as PPIs [8-11]. Apart from this particular curiosity, the antiviral effects of PPIs have been reported by several groups. Moormann et al. filed a patent with priority in 1994 (US-5945425-A) claiming the use of PPIs as antiviral agents [12], Sasaki et al. demonstrated inhibition of rhinovirus infection in cultured human tracheal cells by lansoprazole, by interruption of the RNA endosomal entry reducing the expression of intercellular adhesion molecule-1 [13]. Esomeprazole and omeprazole inhibited entrance of several types of pseudoviruses (EBOV-Z, EBOV-B, MARV, FLU-H5, GALV) in a screen 
of commonly used FDA-approved drugs for the antiviral effects against Ebola [14].

Altogether, evidence suggestive of both the potential detrimental and protective effect of PPIs in the context of viral infections exists. However, the evidence is limited and its invocation and interpretation in the context of COVID-19 requires great caution. Suggested mechanisms responsible for either an increased risk (e.g. removing the protective barrier towards ingested microorganisms [1]) or antiviral effect of PPIs (e.g. modulation of endolysosomal $\mathrm{pH}$ [15]) are still speculative, and studies on other viruses may not be informative about the possible effect of PPIs on the SARS-CoV-2 and COVID-19. For example, although alkalinisation of endolysosomal $\mathrm{pH}$ seems to inhibit the viral entrance of some viruses [16], it has also been shown to increase the infectivity of others [17].

\section{PPIs and COVID-19}

Disclosure of uncertainty and evidence quality is an indispensable part of a well-balanced communication of science [18]. In the light of this fact, we emphasise that both our initial proposal that PPIs might exert beneficial effect [15] and a warning by Charpiat et al. that PPIs might be a risk factor for COVID-19 [1] are based on limited evidence on speculative pathophysiological concepts that should be further explored before affecting clinical decision making. This is particularly so considering that gastroprotection (PPIs) is a standard supportive treatment in severely ill/intubated patients. In order to provide a more balanced overview of the topic of PPIs and COVID-19, we here address several clinical/epidemiological studies published so far dealing with this question.

In a recent retrospective observational study on 152 hospitalised patients with confirmed SARS-CoV-2, Luxenburger et al. reported an increased risk of secondary infections and ARDS after accounting for other predisposing comorbidities [19]. Won Lee et al. conducted a nationwide cohort study on 132,316 patients based on propensity score matching that suggested short-term current, but not long-term current or previous use of PPI might be a risk factor for the development of severe COVID-19, although treatment didn't seem to affect the susceptibility to SARSCoV-2 infection [20]. Zhou et al. found an association between the risk of severe COVID-19 and the use of either PPIs or famotidine in a Chinese cohort of 4445 people after propensity score matching [21]. Almario et al. performed an online survey of 53,130 Americans and reported an independent, dose-response relationship between the use of antisecretory medications and COVID-19 positivity [22]. Ramachandran et al. reported an independent association of prehospitalisation PPI-exposure and worse clinical outcomes in 295 COVID-19 patients [23].
Taken together, the above-mentioned reports support a possibility that the use of PPIs might be a risk factor for developing a more severe clinical presentation of COVID-19 [24-26]. However, they should be interpreted with caution as (i) most of the studies offer limited information on the type, dose, duration, compliance, frequency, concomitant therapy, as well as indication related to PPI treatment [24]; (ii) strength of the observed associations was consistently relatively weak and "in the zone of potential bias" [24, 27]; (iii) most of the studies are retrospective observational cohorts that are prone to bias even after apparently appropriate adjustments. For example, there is a substantial risk of indication bias, and concerns have been raised about the susceptibility to protopathic bias [28], just as in the case of the PPI-pneumonia relationship [27, 29]; (iv) some of the studies included in the meta-analyses suffer from obvious design flaws. For example, the questionable validity of the sampling method evident from the demographics of the cohort in the study by Almario et al. has already been recognised and brought up by others [30-35].

PPIs are a part of a standard supportive care in the most severe COVID-19 patients, but, in the light of the current evidence, the hypothesis that they might confer a significant clinical benefit due to their anti-viral effect [15, 36-38] does not seem likely to be proven correct. Nevertheless, well-controlled prospective studies are needed to provide more solid evidence on the topic as the discovery of either detrimental or beneficial effects of PPIs will likely affect guidelines and clinical decision making given the current widespread use of these drugs.

\section{Declarations}

Funding No funding was received to prepare this letter.

Conflict of interest Authors declare no conflict of interest.

Availability of data Not applicable.

Authors' contributions JH wrote the first draft of the manuscript. IK and VT provided a critical revision of the manuscript. All authors provided final approval of the version to be published.

\section{References}

1. Charpiat B, Bleyzac N, Tod M. Proton pump inhibitors are risk factors for viral infections: even for COVID-19? Clin Drug Investig. 2020;40:897-9.

2. Prag C, Prag M, Fredlund H. Proton pump inhibitors as a risk factor for norovirus infection. Epidemiol Infect. 2017;145:1617-23.

3. Vilcu A-M, Sabatte L, Blanchon T, Souty C, Maravic M, Lemaitre M, et al. Association between acute gastroenteritis and continuous use of proton pump inhibitors during winter periods 
of highest circulation of enteric viruses. JAMA Netw Open. 2019;2:e1916205.

4. Fisher L, Fisher A. Acid-suppressive therapy and risk of infections: pros and cons. Clin Drug Investig. 2017;37:587-624.

5. Sultan N, Nazareno J, Gregor J. Association between proton pump inhibitors and respiratory infections: a systematic review and meta-analysis of clinical trials. Can J Gastroenterol. 2008;22:761-6.

6. Filion KB, Chateau D, Targownik LE, Gershon A, Durand M, Tamim H, et al. Proton pump inhibitors and the risk of hospitalisation for community-acquired pneumonia: replicated cohort studies with meta-analysis. Gut. 2014;63:552-8.

7. Yu L-Y, Sun L-N, Zhang X-H, Li Y-Q, Yu L, Yuan Z-Q-Y, et al. A review of the novel application and potential adverse effects of proton pump inhibitors. Adv Ther. 2017;34:1070-86.

8. Sachs G, Shin JM, Munson K, Scott DR. Gastric acid-dependent diseases: a twentieth-century revolution. Dig Dis Sci. 2014;59:1358-69.

9. Olbe L, Carlsson E, Lindberg P. A proton-pump inhibitor expedition: the case histories of omeprazole and esomeprazole. Nat RevDrug Discov. 2003;2:132-9.

10. Lundell L. The physiological background behind and course of development of the first proton pump inhibitor. Scand J Gastroenterol. 2015;50:680-4.

11. Aguilera-Castro L, Martín-de-Argila-de-Prados C, Albillos-Martínez A. Consideraciones prácticas en el manejo de los inhibidores de la bomba de protone. Revista Española de Enfermedades Digestivas. Sociedad Española de Patología Digestiva/Arán Ediciones, S.L.; 2016;108:145-53.

12. Method of using $(\mathrm{H}+/ \mathrm{K}+)$ ATPase inhibitors as antiviral agents Patent US-5945425-A - PubChem. https://pubchem.ncbi.nlm.nih. gov/patent/US5945425. Accessed 1 Jan 2021.

13. Sasaki T, Yamaya M, Yasuda H, Inoue D, Yamada M, Kubo H, et al. The proton pump inhibitor lansoprazole inhibits rhinovirus infection in cultured human tracheal epithelial cells. Eur J Pharmacol. 2005;509:201-10.

14. Long J, Wright E, Molesti E, Temperton N, Barclay W. Antiviral therapies against Ebola and other emerging viral diseases using existing medicines that block virus entry. F1000Res. 2015;4:30.

15. Homolak J, Kodvanj I. Widely available lysosome targeting agents should be considered as potential therapy for COVID-19. Int J Antimicrob Agents. 2020;56:106044.

16. Brindley MA, Maury W. Endocytosis and a low-pH step are required for productive entry of equine infectious anemia virus. $\mathrm{J}$ Virol. 2005;79:14482-8.

17. Fredericksen BL, Wei BL, Yao J, Luo T, Garcia JV. Inhibition of endosomal/lysosomal degradation increases the infectivity of human immunodeficiency virus. J Virol. 2002;76:11440-6.

18. Blastland M, Freeman ALJ, van der Linden S, Marteau TM, Spiegelhalter D. Five rules for evidence communication. Nature. 2020;587:362-4.

19. Luxenburger H, Sturm L, Biever P, Rieg S, Duerschmied D, Schultheiss M, et al. Treatment with proton pump inhibitors increases the risk of secondary infections and ARDS in hospitalized patients with COVID-19: coincidence or underestimated risk factor? J Intern Med. 2020;289:121-4. https://www.ncbi.nlm.nih. gov/pmc/articles/PMC7361636/.

20. Lee SW, Ha EK, Yeniova AÖ, Moon SY, Kim SY, Koh HY, et al. Severe clinical outcomes of COVID-19 associated with proton pump inhibitors: a nationwide cohort study with propensity score matching. Gut. 2021;70:76-84.

21. Zhou J, Wang X, Lee S, Wu WKK, Cheung BMY, Zhang Q, et al. Proton pump inhibitor or famotidine use and severe COVID-19 disease: a propensity score-matched territory-wide study. Gut. BMJ Publishing Group. 2020;0:1-2. https://gut.bmj.com/conte nt/early/2020/12/08/gutjnl-2020-323668. Accessed 1 Jan 2021.

22. Almario CV, Chey WD, Spiegel BMR. Increased risk of COVID19 Among Users of Proton Pump inhibitors. Am J Gastroenterol. 2020;115:1707-15.

23. Ramachandran P, Perisetti A, Gajendran M, Jean-Louis F, Bansal $\mathrm{P}$, Dwivedi AK, et al. Pre-hospitalization proton pump inhibitor use and clinical outcomes in COVID-19. Eur J Gastroenterol Hepatol. 2020. [Published Ahead of Print]. Accessed 1 Jan 2021.

24. Hariyanto TI, Prasetya IB, Kurniawan A. Proton pump inhibitor use is associated with increased risk of severity and mortality from coronavirus disease 2019 (COVID-19) infection. Digest Liver Dis. 2020;52:1410-2.

25. Kow CS, Hasan SS. Use of proton pump inhibitors and risk of adverse clinical outcomes from COVID-19: a meta-analysis. J Intern Med. 2021;289:125-8.

26. Li G-F, An X-X, Yu Y, Jiao L-R, Canarutto D, Yu G, et al. Do proton pump inhibitors influence SARS-CoV-2 related outcomes? A meta-analysis. Gut. 2020. [Published Online First]. Accessed 1 Jan 2021.

27. Roulet L. A nationwide cohort study with propensity score matching. Gut. BMJ Publishing Group; 2020. https://gut.bmj.com/conte nt/early/2020/10/18/gutjnl-2020-323098. Accessed 1 Jan 2021.

28. Faillie J-L. Indication bias or protopathic bias? Br J Clin Pharmacol. 2015;80:779-80.

29. Wang C-H, Li C-H, Hsieh R, Fan C-Y, Hsu T-C, Chang W-C, et al. Proton pump inhibitors therapy and the risk of pneumonia: a systematic review and meta-analysis of randomized controlled trials and observational studies. Expert Opin Drug Saf. 2019;18:163-72.

30. Almario CV, Chey WD, Spiegel BMR. Increased risk of COVID19 among users of proton pump inhibitors. 2020. https://pubpe er.com/publications/9317268820DED464956F15945D32AD ?utm_source=Chrome\&utm_medium =BrowserExtension\&utm campaign $=$ Chrome. Accessed 1 Jan 2021.

31. Aby ES, Rodin H, Debes JD. Proton Pump Inhibitors and Mortality in Individuals With COVID-19. Am J Gastroenterol. 2020;115:1918.

32. Dahly D, Elia M, Johansen M. A letter of concern regarding increased risk of COVID-19 among users of proton pump inhibitors by Almario, Chey, and Spiegel. Zenodo. 2020. https://zenod o.org/record/3940578\#.Xwn7meco-Uk. Accessed 1 Jan 2021.

33. Hajifathalian K, Katz PO. Regarding "Increased Risk of COVID19 in patients taking proton pump inhibitors." Am J Gastroenterol. 2020;115:1918-9.

34. Hadi YB, Naqvi SF, Kupec JT. Risk of COVID-19 in patients taking proton pump inhibitors. Am J Gastroenterol. 2020. https:// www.ncbi.nlm.nih.gov/pmc/articles/PMC7553029/. Accessed 1 Jan 2021.

35. Tarlow B, Gubatan J, Khan MA, Cholankeril G. Are proton pump inhibitors contributing to SARS-COV-2 infection? Am J Gastroenterol. 2020. https://www.ncbi.nlm.nih.gov/pmc/articles/PMC75 05035/. Accessed 1 Jan 2021.

36. Taştemur Ş, Ataseven H. Is it possible to use proton pump inhibitors in COVID-19 treatment and prophylaxis? Med Hypotheses. 2020;143:110018.

37. Ray A, Sharma S, Sadasivam B. The Potential therapeutic role of proton pump inhibitors in COVID-19: hypotheses based on existing evidences. Drug Res (Stuttg). 2020;70:484-8.

38. Conrad KP. Might proton pump or sodium-hydrogen exchanger inhibitors be of value to ameliorate SARs-CoV-2 pathophysiology? Physiol Rep. 2021;8:e14649. 